\title{
PREDICTION OF ANGLE OF INTERNAL FRICTION OF SAND USING GRAIN-SIZE DISTRIBUTION CURVE
}

\author{
Mostafa Abdou Abd El-Naiem \\ Lecturer, Civil Eng. Department, Faculty of Eng., Assiut University, \\ Assiut, Egypt
}

(Received January 1, 2008 Accepted January 21, 2008)

The shear strength parameters play an important role in many practices for geotechnical engineering. To determine the real values of these parameters requires undisturbed samples and that is difficult for cohesionless soil. So, prediction of shear strength parameter such as angle of internal friction in the case of cohesionless soil with the help of grainsize distribution provides a good opportunity to obtain this parameter without using of more laboratory tests. The grain-size distribution is commonly used for soil classification, design of filters, and ....etc. This study was undertaken in order to quantify the variation of the values of angle of internal friction due to variation of contents of sand soil between fine, medium, coarse sand, or mixtures from some or all of these types. Many types of sand soil have been investigated for this purpose. Shear box tests were conducted using samples of different dry densities. This paper proposed new empirical equations and curves to predict the angle of internal friction for sand soil using the grain-size distribution curve.

KEYWORDS: Grain-size distribution, Shear strength parameters, Angle of internal friction, Sieve analysis, Density, Sand.

\section{INTRODUCTION}

The grain-size distribution is a simple, yet informative test routinely performed in soil mechanics. It is commonly used for soil classification; however there is also potential to use the grain-size distribution as a basis for estimating soil behavior. For example, much emphasis has recently been placed on the estimation of the soil-water characteristic curve. Theoretically representing the grain-size distribution provides several benefits. First, the soil may be classified using the best-fit parameters. Second, the mathematical equation can be used as a basis for analysis related to estimating the soil-water characteristic curve. Third, a mathematical equation can provide a method of representing the entire curve between measured data points, fredlund et al. [1]. Numerous methods have been developed for determination the angle of internal friction. These methods include the field and laboratory tests. Also, to determine the real value of angle of internal friction $(\varphi)$, special techniques should be followed such as undisturbed samples and this is difficult for cohesionless soil, type of shear strength test, and initial overburden pressures should be taken into consideration. On the other hand, only the grain-size distribution curve does not depend on undisturbed sample. The interpretation of the grain-size distribution is typically carried out manually and mechanically. Further details concerning the testing procedure of the sieve analysis test 
are provided by many references related to soil mechanics and as mentioned in the Egyptian code of soil mechanics and foundations design [2]. There are three general categories of grain-size distributions well-graded, uniform, and gap-graded. The grainsize distribution curve provides information on the distribution of the solid phase of the soil. Since the solids plus the voids add up to the total soil volume, it is to be expected that the distribution of the solids phase (i.e., grain-size distribution) would tend to bear an inverse relationship to the distribution of voids and vice versa [1]. The relation between solids and voids can be represented by dry density which can be determined in the field. In spite of difficulties obtaining undisturbed sample from sand soil, but Pralle et al. [3] stated that conventional sampling methods fail to produce undisturbed samples from loose sands below groundwater level. However, the soil-freezing method has proven to cause the least disturbance possible in such soils. Although freezing soil does not maintain the sample in its original state of stress, structure and texture are well preserved under the premise that the soil has been subjected to the least possible disturbance during installation of the necessary equipments.

This study was undertaken in order to quantify the variation of the values of angle of internal friction due to variation of content of sand soil between fine, medium, coarse sand, or combination from all of these. Shear box tests were conducted using samples of different dry densities as used by Hamdy [5]. Also, this paper proposed a new method to identify the angle of internal friction $(\varphi)$ for sand soil using grain-size distribution curve. Many types of sand soil have been investigated for this purpose.

\section{EXPERIMENTAL WORK}

In the present study, seven specimens of sand with different grain-size distribution have been studied. To carry out the sieve analysis test, the sand soil was washed on sieve has opening of $0.063 \mathrm{~mm}$ to make sure that its do not include any percentage of fine soil. To determine the angle of internal friction $(\varphi)$, a direct shear box test was used. According to the procedure of the test, there are three different tests Unconsolidated-undrainded test, Consolidated-undrained test, and Consolidateddrained test. Bowles (1986) mentioned that for cohesionless soil, all three of the above tests will give the same results, whether the sample is saturated or unsaturated and, of course, if the shearing rate is not extremely rapid [4].

\subsection{Soil Description and its Properties}

The used soil for the tests is sand with different types. Seven specimens of sand with different grain-size distribution have been chosen and denoted as sand I, II, III, IV, V, VI, and sand VII. The sieve analysis tests were carried out to determine the grain size distribution curve of the tested sand soils as shown in Figures 1 and 2. The properties of the used sand soils such as effective diameter $\left(D_{10}\right)$ and $D_{30}, D_{50}, D_{60}, D_{85}$ uniformity coefficient $\left(\mathrm{U}_{\mathrm{c}}\right)$, and coefficient of curvature $\left(\mathrm{C}_{\mathrm{c}}\right)$ are tabulated in Table 1 . It can be found that sand I, sand II, and sand III are approximately coarse, medium, and fine sand, respectively. Whereas, sand IV, sand V, sand VI and sand VII are consist of the three types of sand with different ratios as shown in Figure 2. The contents of the used sand soil, (fine, medium, and coarse), in all specimens are tabulated as shown in Table 2. 


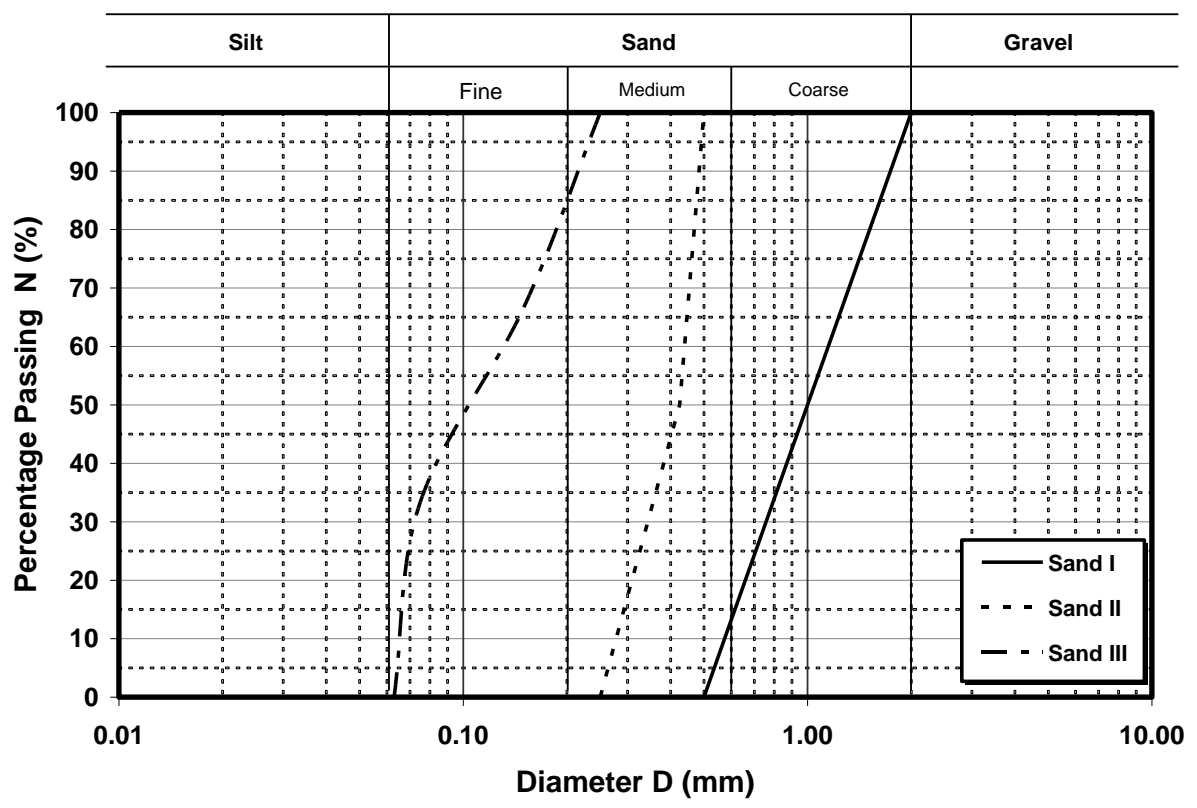

Figure 1. Grain-size distribution curves for the tested sand soils I, II, III

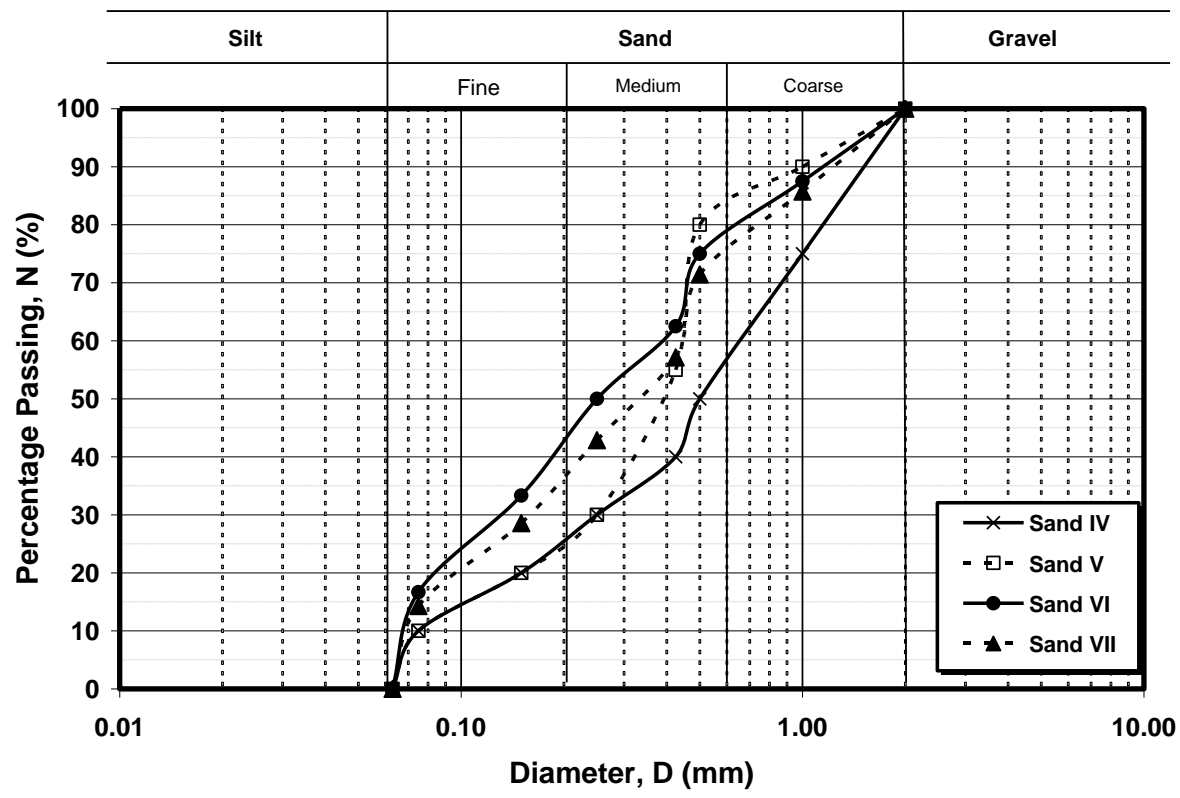

Figure 2. Grain-size distribution curves for the tested sand soils IV, V, VI, VII 
Table 1. Properties of the used sand soils

\begin{tabular}{|c|c|c|c|c|c|c|c|}
\hline Specimen & $\begin{array}{c}\mathrm{D}_{10} \\
(\mathrm{~mm})\end{array}$ & $\begin{array}{c}\mathrm{D}_{30} \\
(\mathrm{~mm})\end{array}$ & $\begin{array}{c}\mathrm{D}_{50} \\
(\mathrm{~mm})\end{array}$ & $\begin{array}{c}\mathrm{D}_{60} \\
(\mathrm{~mm})\end{array}$ & $\begin{array}{c}\mathrm{D}_{85} \\
(\mathrm{~mm})\end{array}$ & $\mathrm{U}_{\mathrm{c}}$ & $\mathrm{C}_{\mathrm{c}}$ \\
\hline Sand I & 0.51 & 0.71 & 1.0 & 1.14 & 1.56 & 2.0 & 0.78 \\
\hline Sand II & 0.28 & 0.35 & 0.41 & 0.44 & 0.49 & 1.57 & 1.0 \\
\hline Sand III & 0.064 & 0.071 & 0.1 & 0.13 & 0.2 & 2.03 & 0.61 \\
\hline Sand IV & 0.072 & 0.24 & 0.5 & 0.62 & 1.32 & 8.61 & 1.29 \\
\hline Sand V & 0.072 & 0.24 & 0.4 & 0.44 & 0.6 & 6.11 & 1.82 \\
\hline Sand VI & 0.066 & 0.16 & 0.23 & 0.44 & 0.9 & 6.67 & 0.88 \\
\hline Sand VII & 0.065 & 0.13 & 0.32 & 0.37 & 1.0 & 5.69 & 0.7 \\
\hline
\end{tabular}

Where $\quad U_{c}=\frac{D_{60}}{D_{10}} \quad$ and $\quad C_{c}=\frac{\left(D_{30}\right)^{2}}{D_{60} \times D_{10}}$

Table 2. Contents of the used sand soils

\begin{tabular}{|c|c|c|c|}
\hline \multirow{2}{*}{ Specimen } & \multicolumn{3}{|c|}{ Percentage of different types of sand (\%) } \\
\cline { 2 - 4 } & Fine sand & Medium sand & Coarse sand \\
\hline Sand I & 85 & 15 & 0 \\
\hline Sand II & 0 & 100 & 0 \\
\hline Sand III & 0 & 15 & 85 \\
\hline Sand IV & 25 & 31 & 44 \\
\hline Sand V & 24 & 62 & 14 \\
\hline Sand VI & 43 & 36 & 21 \\
\hline Sand VII & 27 & 48 & 25 \\
\hline
\end{tabular}

\subsection{Study Cases}

There are seven different sand soils are obtained to determine the angle of internal friction. Three different values of dry density $\left(\gamma_{\mathrm{d}}\right)$ for each type of sand soils, 1.5, 1.6, and $1.7 \mathrm{gm} / \mathrm{cm}^{3}$ were used. All tests were carried out according to the Egyptian code of soil mechanics and foundations design [2]. The tests can be carried out mechanically or manually. To obtain any certain value of dry density, the sand is placed into a shear box having a known volume by a specific designed weight.

\section{ANALYSIS OF RESULTS AND DISCUSSIONS}

In the following sections, the results obtained from experimental tests are presented and discussed. Three groups of tests for three values of dry density $\left(\gamma_{\mathrm{d}}=1.5,1.6\right.$, and $1.7 \mathrm{gm} / \mathrm{cm}^{3}$ ) were performed. Each group includes the tests required to determine the angle of internal friction $(\varphi)$ for seven different types of sand soils as mentioned before. The results obtained from all tests are tabulated in Table 3 . This table includes average diameter $D_{a v}$ and values of angle of internal friction $(\varphi)$ for seven different types of sand soils and three groups having three previous values of dry density. 
Table 3. Values of average diameter and test results

\begin{tabular}{|c|c|c|c|c|}
\hline \multirow{2}{*}{ Specimen } & \multirow{2}{*}{$\begin{array}{c}\mathrm{D}_{\mathrm{av}} \\
(\mathrm{mm})\end{array}$} & \multicolumn{3}{|c|}{ Values of angle of internal friction $(\varphi)^{\circ}$} \\
\cline { 3 - 5 } & & $\begin{array}{c}\text { Group I } \\
\gamma_{\mathrm{d}}=1.5 \\
\left(\mathrm{gm} / \mathrm{cm}^{3}\right)\end{array}$ & $\begin{array}{c}\text { Group II } \\
\gamma_{\mathrm{d}}=1.6 \\
\left(\mathrm{gm} / \mathrm{cm}^{3}\right)\end{array}$ & $\begin{array}{c}\text { Group III } \\
\gamma_{\mathrm{d}}=1.7 \\
\left(\mathrm{gm} / \mathrm{cm}^{3}\right)\end{array}$ \\
\hline Sand I & 0.996 & 40.56 & 43.46 & 45.85 \\
\hline Sand II & 0.394 & 36.36 & 40.25 & 46.60 \\
\hline Sand III & 0.113 & 33.53 & 37.04 & 40.24 \\
\hline Sand IV & 0.55 & 34.62 & 38.36 & 39.62 \\
\hline Sand V & 0.35 & 33.16 & 38.03 & 40.24 \\
\hline Sand VI & 0.36 & 33.16 & 39.94 & 42.89 \\
\hline Sand VII & 0.377 & 32.42 & 39.32 & 44.00 \\
\hline
\end{tabular}

Where

$$
D_{a v}=\frac{D_{10}+D_{30}+D_{50}+D_{60}+D_{85}}{5}
$$

\subsection{Angle of internal friction versus dry density}

Figures 3 and 4 show the relationships between dry density of sand and the angle of internal friction $(\varphi)$ for different types of sand soils.

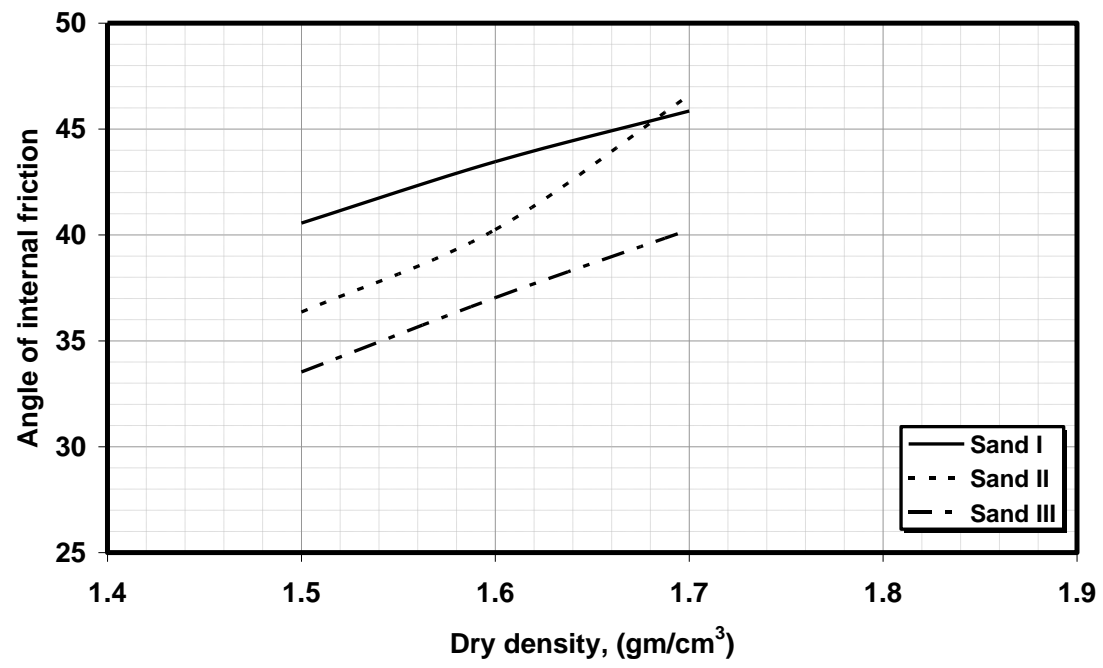

Figure 3. Angle of internal friction versus dry density for sand soils I, II, and III.

From Figure 3, it can be noticed that the angle of internal friction increases as dry density increases. Also, it can be found that by increasing the particle size the angle of internal friction increases too and this clear in sand I which consists of coarse sand, whereas, sand II and sand III consist of medium and fine sand, respectively and that is for the same type of sand also. 


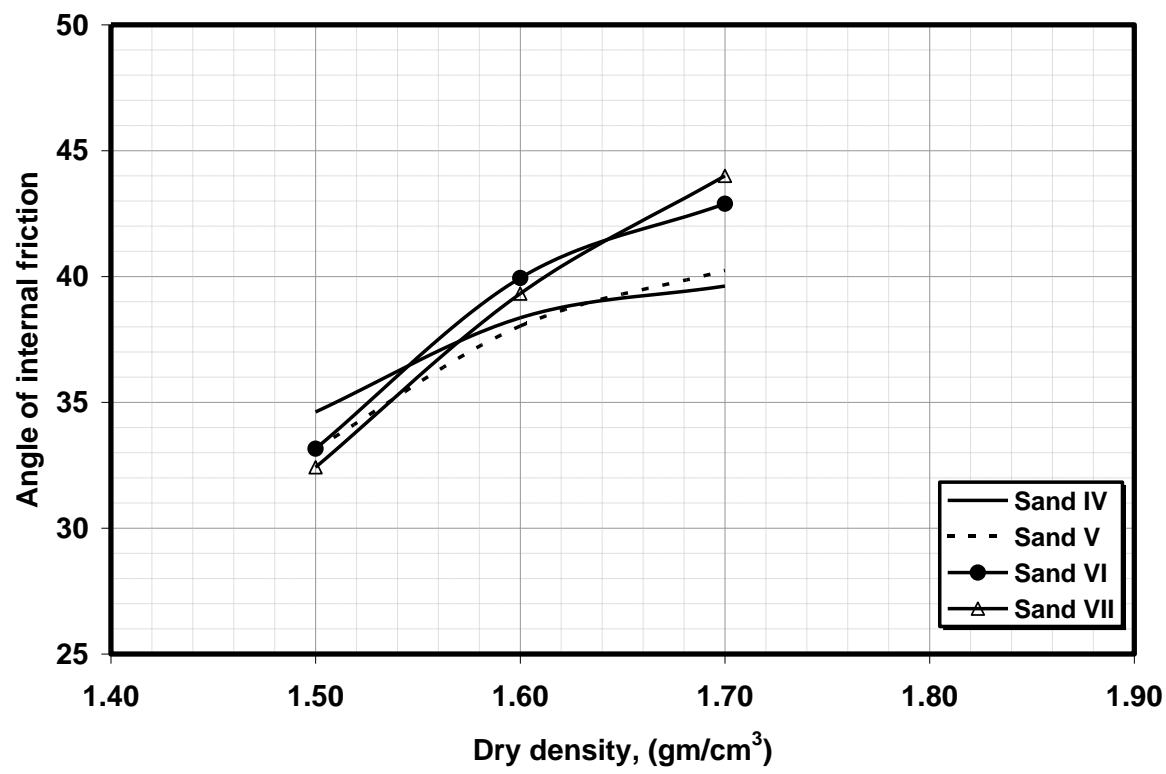

Figure 4. Angle of internal friction versus dry density for sand soils IV, V, VI, and VII.

From Figure 4, it can be noticed that the angle of internal friction increases as dry density increases. Also, it can be found that, in the case of dry density equal to 1.5 $\mathrm{gm} / \mathrm{cm}^{3}$, by increasing the percentage of coarse sand the angle of internal friction increases too and this clear in sand IV which approximately consists of $44 \%$ from coarse sand, whereas, sand V, sand VI and sand VII consist of high percentage from medium and fine sand, respectively. In the case of dry density equal to 1.6 and 1.7 $\mathrm{gm} / \mathrm{cm}^{3}$, because the summation of percentages of fine and medium sand are higher than percentage of coarse sand, especially, in the specimens of sand V, sand VI, and sand VII, so, the value of angle of internal friction is higher that for sand IV. This may be due to the insertion of fine and medium particle in the voids of coarse sand to make the specimens are less voids and the friction surface increases. Also, this leads to the surface of shear as general shear failure.

\subsection{Angle of internal friction versus average diameter $\left(D_{a v}\right)$}

Figures 5 and 6 show the relationships between average diameters $\left(D_{a v}\right)$ of sand soils and the angle of internal friction $(\varphi)$ for different types of sand soils. Figure 5 shows the relationships for sand soils consist of one type of sand, (fine, medium, or coarse sand), such as specimens sand I, II, and III, whereas Figure 6 for sand soils consist of all different types fine, medium, and coarse sand with different ratios such as specimens sand IV, V, VI, and VII. 


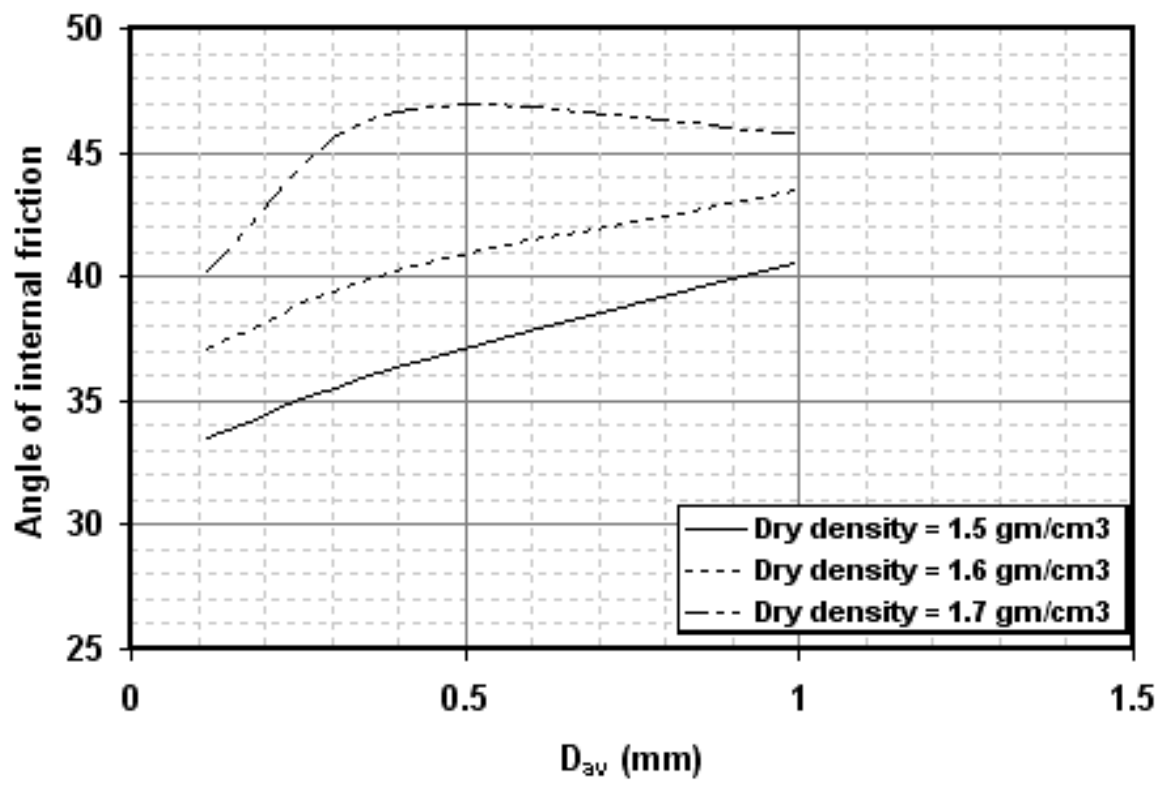

Figure 5. Angle of internal friction versus average diameter $\left(D_{\text {av }}\right)$ for sand soils I, II, and III.

From Figure 5 and Table 3, it can be noticed that, , in the case of dry density equal to 1.5 or $1.6 \mathrm{gm} / \mathrm{cm}^{3}$, the angle of internal friction increases as average dry density increases. whereas, in the case of dry density equal to $1.7 \mathrm{gm} / \mathrm{cm}^{3}$, it can be found that by increasing the average dry density results in increasing in the value of angle of internal friction until certain value of $D_{a v}$ equal to $0.5 \mathrm{~mm}$ after that a slightly decreasing in the value of angle of internal friction occurred. Looking for a curve in the case of dry density equal to $1.7 \mathrm{gm} / \mathrm{cm}^{3}$, the beginning of curve represents a fine sand (sand III), then up to $\mathrm{D}_{\mathrm{av}}$ equal to $0.5 \mathrm{~mm}$ represents a medium sand (sand II), whereas, the end of curve represents coarse sand (sand I). This leads to, in the case of coarse sand; still the case of local shear failure is the dominant and this may be due to decreasing in the contact surface between solid particles in the case of coarse sand.

From Figure 6 and Table 3, it can be found that when $D_{a v}$ is less than $0.37 \mathrm{~mm}$ this case represents the specimens of sand V, VI, and VII, whereas, when $\mathrm{D}_{\mathrm{av}}$ is more than $0.38 \mathrm{~mm}$ this case represents the specimen of sand VII. It can be noticed that, in the case of $D_{a v}$ less than $0.38 \mathrm{~mm}$, for dry density $=1.5 \mathrm{gm} / \mathrm{cm}^{3}$ the angle of internal friction decreases as $D_{a v}$ increases after that it increases as $D_{a v}$ increases and the rate of increasing is small. On the other hand, for dry density $=1.6$ or $1.7 \mathrm{gm} / \mathrm{cm}^{3}$ the angle of internal friction increase as $\mathrm{D}_{\mathrm{av}}$ increases until $\mathrm{D}_{\mathrm{av}} \approx 0.375 \mathrm{~mm}$ after that it decreases as $D_{a v}$ increases; and the rate of decreasing in case of dry density $=1.7 \mathrm{gm} / \mathrm{cm}^{3}$ is more than that in the case of dry density $=1.6 \mathrm{gm} / \mathrm{cm}^{3}$. 


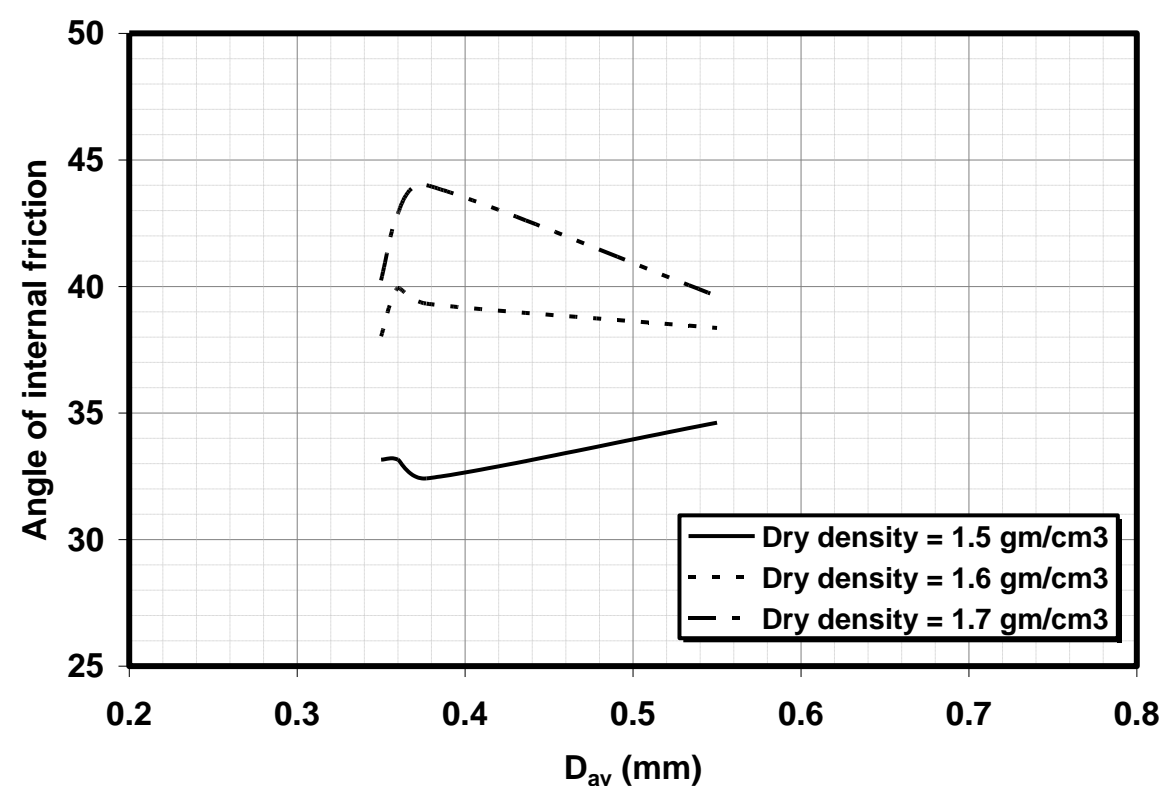

Figure 6. Angle of internal friction versus average diameter $\left(D_{a v}\right)$ for sand soils IV, V, VI, and VII.

From the previous discussion it can be concluded that all types of sand (fine, medium, and coarse) affect on the value of angle of internal friction $(\varphi)$. The effect of coarse sand is clear in sand specimens having low dry densities, whereas, in the case of sand specimens having high dry densities the effect of fine and medium sands in the value of angle of internal friction $(\varphi)$ is more than those having low dry densities and this is attributed to the particles of fine and medium sands inserted to fill the voids between particles of coarse sand. This is clear in the case of sand specimens having dry density $=1.6$ or $1.7 \mathrm{gm} / \mathrm{cm}^{3}$ due to increasing in the contact surface between solid particles in the case of specimens having all types of sand.

\subsection{Empirical equations to predict the angle of internal friction}

From the above test results shown in the Figures 5 and 6 and regression analysis, empirical equations to estimate the value of angle of internal friction $(\varphi)$ for different cases of densities and sand specimens with different values of average diameter $\left(\mathrm{D}_{\mathrm{av}}\right)$ are predicted. There are two cases of specimens as follows:

a) Case of the specimens consist of one type of sand, (fine, medium, or coarse)

where

$$
\begin{gathered}
\varphi=a_{1}\left(D_{a v}\right)^{2}+b_{1}\left(D_{a v}\right)+c_{1} \\
a_{1}=-117.65\left(\gamma_{d}\right)+175.76 \\
b_{1}=122.45\left(\gamma_{d}\right)-174.88 \\
c_{1}=21.2\left(\gamma_{d}\right)+0.8
\end{gathered}
$$

where $D_{a v}$ is the average diameter in $m m$ and $\gamma_{d}$ is the dry density in $\left(\mathrm{gm} / \mathrm{cm}^{3}\right)$. 
The above equations have coefficients correlation $\left(R^{2}\right)$ range from 0.92 to 0.96 , which are considered very good. The factors $\mathrm{a}_{1}, \mathrm{~b}_{1}$, and $\mathrm{c}_{1}$ can also be obtained from curves shown in Figure 7.

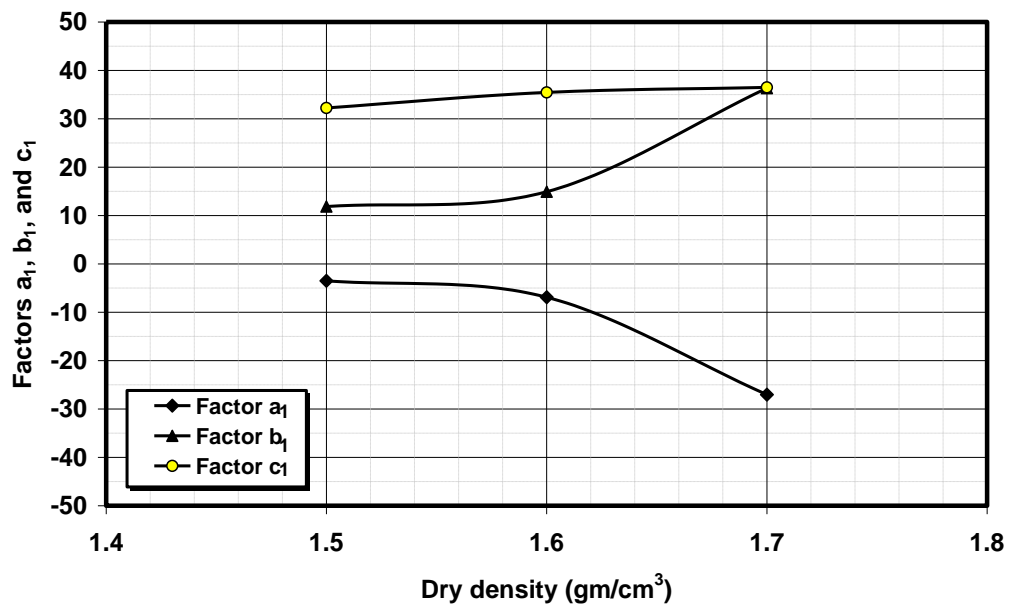

Figure 7. Factors $a_{1}, b_{1}$, and $c_{1}$ versus dry density for sand soils I, II, and III.

b) Case of the specimens consist of all types of sand, (fine, medium, and coarse)

where

$$
\begin{aligned}
\varphi & =a_{2}\left(D_{a v}\right)^{2}+b_{2}\left(D_{a v}\right)+c_{2} \\
a_{2} & =-5054.9\left(\gamma_{d}\right)+7806.1 \\
b_{2} & =4489.5\left(\gamma_{d}\right)-6929.5 \\
c_{2} & =-915.1\left(\gamma_{d}\right)+1447.4
\end{aligned}
$$

The above equations have coefficients correlation $\left(R^{2}\right)$ ranged between 0.99 and 1.0, are considered very good. The factors $\mathrm{a}_{2}, \mathrm{~b}_{2}$, and $\mathrm{c}_{2}$ can also be obtained from curves shown in Figure 8.

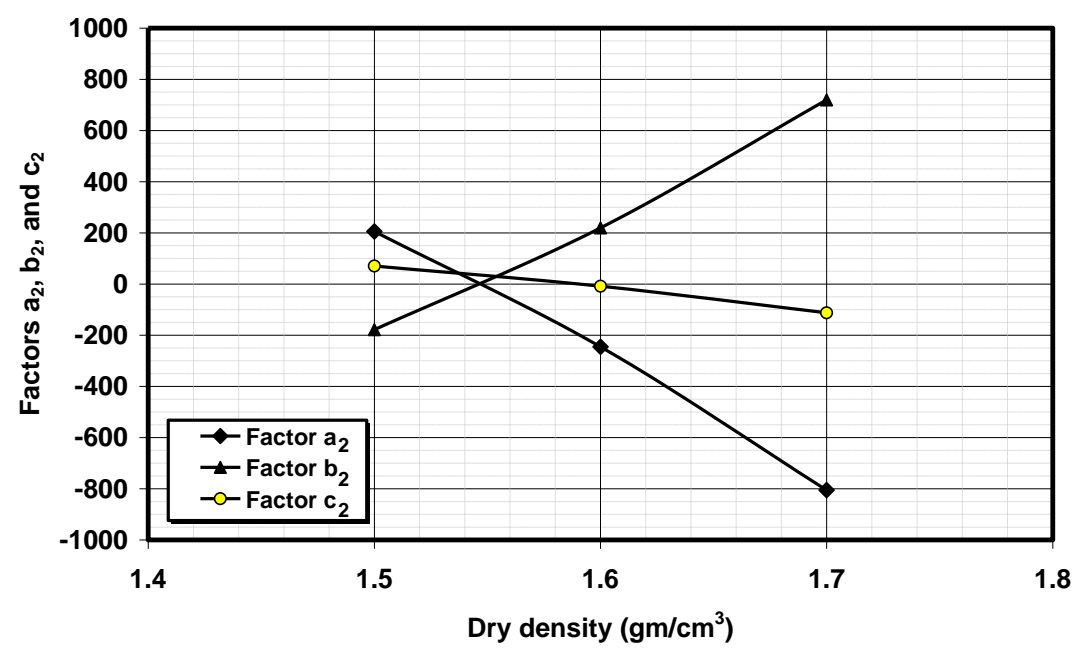

Figure 8. Factors $\mathrm{a}_{2}, \mathrm{~b}_{2}$, and $\mathrm{c}_{2}$ versus dry density for sand soils IV, V, VI and VII. 


\section{CONCLUSIONS}

The present study is concerned with the prediction of angle of internal friction for sand soils with the help of grain-size distribution curves. In this study, the main parameters were taken into consideration are slope dry density $\left(\gamma_{d}\right)$ and average diameter $\left(D_{a v}\right)$ of sand soils.

Based on the presented discussion and analysis of obtained results, the following main conclusions are summarized as:

1) The angle of internal friction increases as particle size of each type of sand (fine, medium, or coarse) increases.

2) The angle of internal friction increases as dry density increases and this is valid for all specimens of sand soil.

3) In the case of low dry densities (near to loose state) by increasing the percentage of coarse sand the angle of internal friction increases too.

4) In the case of high dry densities (near to medium or dense state) by increasing the summation of percentages of fine and medium sand results in an increasing in the angle of internal friction due to insertion of these particles between coarse particle to increase contact shear surface as general shear failure.

5) In the cases of low dry densities or sand specimens consist of one type the angle of internal friction increases as average diameter $\left(D_{a v}\right)$ increases, whereas, in the case of high dry densities and sand specimens having all types of sand, it decreases as $\left(\mathrm{D}_{\mathrm{av}} \geq 0.37\right)$ increases.

6) Empirical equations to predict the angle of internal friction for sand soils were presented as:

a) Case of specimens consist of one type of sand, (fine, medium, or coarse)

$$
\varphi=a_{1}\left(D_{a v}\right)^{2}+b_{1}\left(D_{a v}\right)+c_{1}
$$

b) Case of specimens consist of all types of sand, (fine, medium, and coarse)

$$
\varphi=a_{2}\left(D_{a v}\right)^{2}+b_{2}\left(D_{a v}\right)+c_{2}
$$

where $a_{1}, b_{1}, c_{1}, a_{2}, b_{2}$, and $c_{2}$ were mentioned before.

\section{REFERENCES}

1. Fredlund, M.D., Fredlund, D.G., and Wilson, G.W., "An Equation to Represent Grain-Size Distribution," Canadian Geotechnical Journal, Vol. 37, pp. 817-827, (2000).

2. "Egyptian Code for Soil Mechanics \& Design and Construction of Foundations, Laboratory Tests," Part 2, (2001).

3. Pralle, N., Bahner, M.L., and Benkler, J., "Computer Tomographic Analysis of Undisturbed samples of Loose sands," Canadian Geotechnical Journal, Vol. 38, pp. 770-781, (2001).

4. Bowles, J. E., "Engineering Properties of Soils and Their Measurements," McGraw-Hill Book Company, Singapore, (1986).

5. Hamdy, D.B., "Geotechnical Properties of Shelly Sand at Hurgada," $11^{\text {th }}$ International Colloquium on Structural and Geotechnical Engineering, ICSGE, Ain Shams University, Cairo, Egypt, May 17-19, (2005). 


\section{التكهن بقيمة زاوية الأحتكاك الداخلى للتربة الرملية بإستخدام \\ منحنيات التدرج الحبيبى}

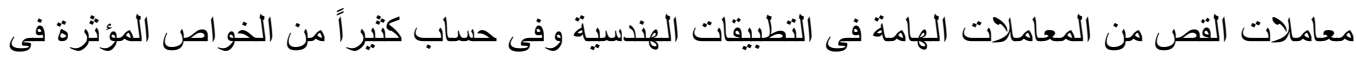

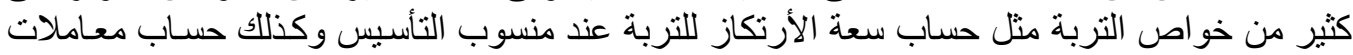

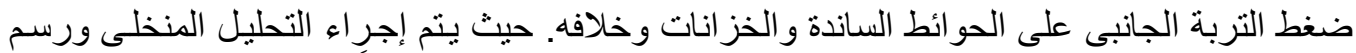

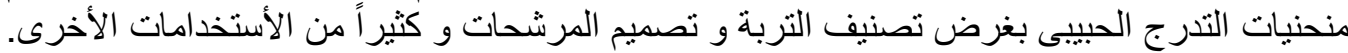

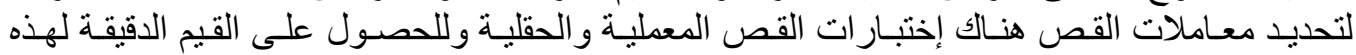

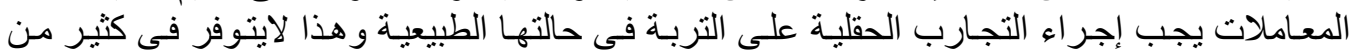

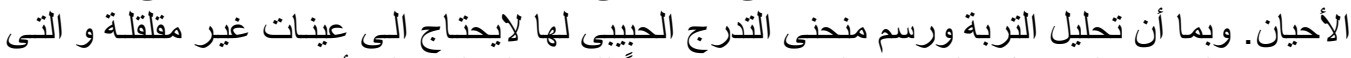

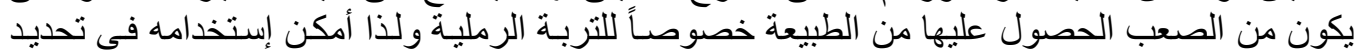

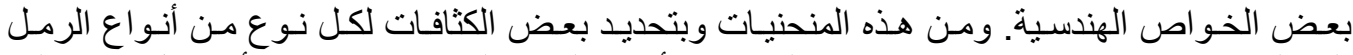

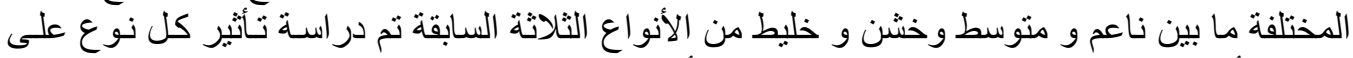

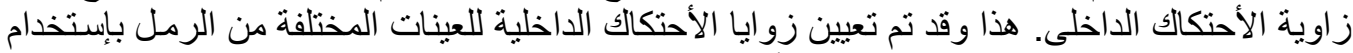

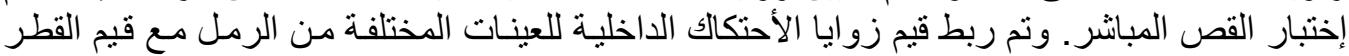

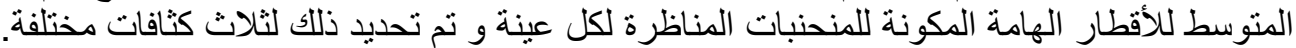

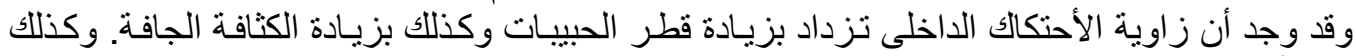

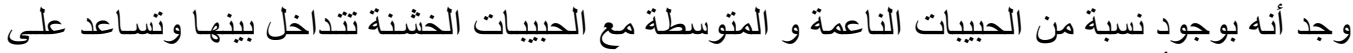

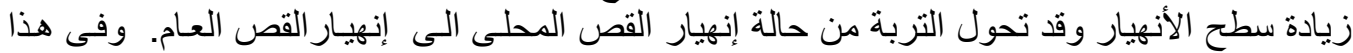

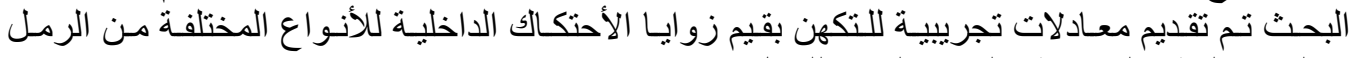

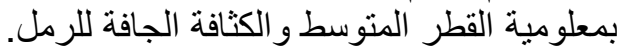

